\title{
Peripheral nerve conduction in metachromatic leucodystrophy (sulphatide lipidosis)
}

\author{
PAMELA M. FULLERTON ${ }^{1}$ \\ From the Institute of Neurology, Queen Square, London
}

In recent years there has been increasing interest in peripheral nerve abnormalities in metachromatic leucodystrophy (sulphatide lipidosis). Previously attention was concentrated on the central nervous system, the involvement of which dominates the clinical and pathological picture. However, Brain and Greenfield (1950) described metachromatic granules in nerve roots of the cauda equina in one of the four cases they studied. Later Norman, Urich, and Tingey (1960) reported similar granules in association with broken up myelin sheaths in the sciatic nerve of one case. Jacobi (1947) and Bertrand, Thieffry, and Bargeton (1954) have also described peripheral nerve involvement at necropsy.

The diagnostic value of peripheral nerve biopsy has now become recognized (Thieffry and Lyon, 1959; Hagberg, Sourander, and Thorén, 1962). Webster (1962) has made a detailed study, by phase contrast and electron microscopy, of sural nerve biopsy specimens from two patients with this condition. Similar changes have been reported by all these authors. Metachromatic granules with the same properties as those found in the cerebral hemispheres were seen. These were most numerous in Schwann cells and were present to a lesser extent beside degenerating myelin sheaths. The nerve fibres showed patchy breakdown of myelin with preservation of normal axon structure, and Webster (1962) described this segmental demyelination as very similar to that seen in experimental diphtheritic neuritis (Webster, Spiro, Waksman, and Adams, 1961). Similar histological changes are seen in autonomic nerve fibres, and Bodian and Lake (1963) have described their appearance in specimens obtained by rectal biopsy.

In view of these pathological findings, an electrophysiological study of nerve conduction in children suffering from metachromatic leucodystrophy has been carried out. A preliminary report has already been published (Fullerton, 1963). These cases are to be reported in greater detail by $\mathrm{H}$. Metz (to be published) and only brief clinical descriptions are given here.

${ }^{1}$ In receipt of a personal grant from the Medical Research Council.
MATERIAL AND METHODS

Seven children, three male and four female, suffering from metachromatic leucodystrophy have been investigated. In all cases the diagnosis has been confirmed by biopsy. Cerebral biopsy was performed in three cases, peripheral nerve biopsy in five, and rectal biopsy in all. Their ages ranged from 2 to 9 years; two pairs of siblings are included. Clinical summaries are given in the Appendix. Cases 1, 2, 3 and 6 are included in the report by Bodian and Lake (1963) of histological changes in rectal biopsy specimens.

The patients were examined lying on a couch in a warm room. The skin temperature over the flexor aspect of the forearm or dorsum of the foot varied between $33.5^{\circ} \mathrm{C}$ and $36^{\circ} \mathrm{C}$. in different patients at the time the recordings were made.

Motor nerve conduction velocity was estimated b了 stimulating peripheral nerves through the skin and record ing muscle action potentials through surface electrodes: placed over one of the small muscles of the hand or foot. For stimulation, pad electrodes $1 \mathrm{~cm}$. in diameter were used. In the arm, a cathode was held over the course of the ulnar or median nerve at the wrist, at the elbow, or in the axilla. An anode was strapped over the outer side of the upper arm. The arrangement of electrodes for the ulnar nerve is shown in Figure 1. In the leg, cathodes were held over the anterior tibial nerve at the ankle or the lateral popliteal nerve at the head of the fibula. The anode was situated on the medial side of the thigh. The stimulus was a condenser discharge with a time constant of $150 \mu \mathrm{sec}$., delivered through an isolating transformer (output impedance $500 \mathrm{ohms}$ ). The voltage was continuously variable up to 300 volts and was adjusted to be supramaximal for motor fibres. In one case supramaximal stimulation could not be achieved with this stimulator and a square wave of $3 \mathrm{~m} . \mathrm{sec}$. duration was applied from a stimulator designed by Thomas and Morton (1963).

Muscle action potentials were recorded through silver cup electrodes $1 \mathrm{~cm}$. in diameter fixed over the belly and tendon of the abductor digiti minimi, abductor pollicis brevis, or extensor digitorum brevis.

The potentials were amplified through conventional RC coupled amplifiers and displayed on one beam of a double-beam cathode ray oscilloscope, the second beam carrying a time scale. Single responses were photographed and conduction time measured from the stimulus artefact to the onset of the negative deflection of the action poten- 

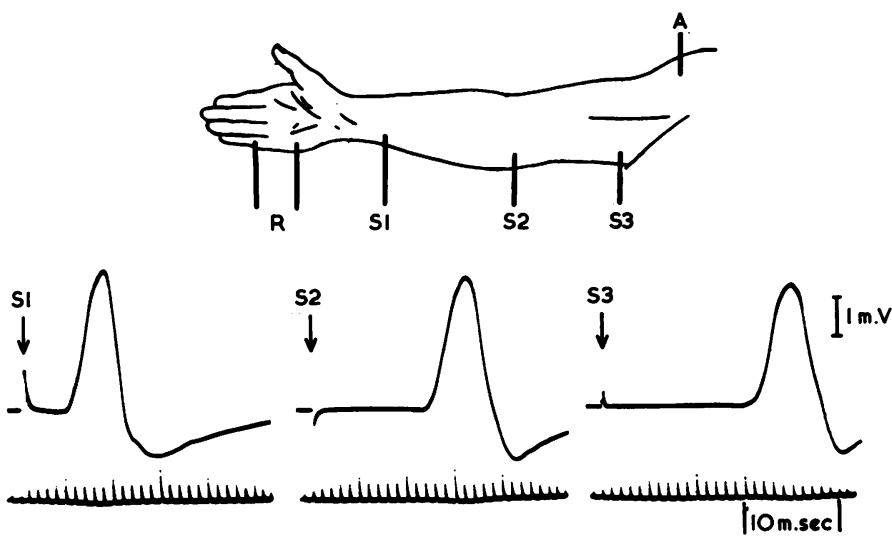

FIG. 1. Case 1. Diagram of electrode arrangement (for details, see text), and muscle action potentials recorded from abductor digiti minimi with stimulation of ulnar nerve at wrist (S.I), elbow (S.2) and axilla (S.3). tial. The distance between cathode positions was measured on the skin and gave an estimate of nerve length, enabling calculation of conduction velocity in the fastest motor fibres. The height of the main negative deflection of the action potential above the base line was compared with a calibration pulse and gave an estimate of action potential amplitude.

In one case in which motor nerve conduction velocity measurements were normal, nerve action potentials were recorded using a technique similar to that described by Dawson (1956). Action potentials were recorded through surface electrodes over the ulnar nerve at the wrist following stimulation of digital nerve fibres through ring electrodes and from the ulnar nerve just above the elbow when the nerve was stimulated at the wrist.

\section{RESULTS}

Figure 1 shows the muscle action potentials recorded from the abductor digiti minimi in case 1 when the ulnar nerve was stimulated at the wrist, elbow, and axilla. Conduction velocities in motor fibres of the ulnar nerves of the seven children are shown in Table I. Thomas and Lambert (1960) measured motor nerve conduction velocity in the ulnar nerve in the forearm in healthy children of different ages using a technique similar to that of the present study. They found that from the age of 5 years conduction velocities were within the normal adult range of 47 to $73 \mathrm{~m} . / \mathrm{sec}$. Between the ages of 2 and 5 years velocities were in the lower part of the adult range. Figure 2 is modified from Thomas and Lambert (1960) and shows their results for healthy children. The results in patients with metachromatic leucodystrophy have been added and it can be seen that there was a marked reduction of conduction velocity in six of the seven patients. The slowest velocity recorded was $11.1 \mathrm{~m} . / \mathrm{sec}$. (case 3 ). In the siblings L.F. and D.F. (cases 4 and 5) the more severely affected older child had a conduction velocity of $19.0 \mathrm{~m} . / \mathrm{sec}$. in the forearm, whereas her younger brother, who was much less severely affected, had a higher conduction velocity $(33.4 \mathrm{~m} . / \mathrm{sec}$.).

In adults motor nerve conduction velocity in the upper arm is slightly faster than in the forearm. Gilliatt and Thomas (1960) found a mean velocity

TABLE I

MOTOR NERVE CONDUCTION IN ULNAR NERVE

\begin{tabular}{|c|c|c|c|c|c|c|}
\hline \multirow[t]{2}{*}{ Patient } & \multirow[t]{2}{*}{ Age } & \multirow[t]{2}{*}{ Nerve } & \multirow{2}{*}{$\begin{array}{l}\text { Amplitude } \\
(m V)\end{array}$} & \multirow{2}{*}{$\begin{array}{l}\text { Latency } \\
\text { Wrist to Muscle } \\
\text { (m.sec.) }\end{array}$} & \multicolumn{2}{|c|}{ Conduction Velocity } \\
\hline & & & & & $\begin{array}{l}\text { Elbow to Wrist } \\
(\mathrm{m} . / \mathrm{sec} .)\end{array}$ & $\begin{array}{l}\text { Axilla to Elbow } \\
(\mathrm{m} . / \mathrm{sec} .)\end{array}$ \\
\hline Case 1 E.D. & 2 yr. $7 \mathrm{mth}$. & $\begin{array}{l}\text { R. ulnar } \\
\text { L. ulnar }\end{array}$ & $\begin{array}{l}3.9 \\
3.0\end{array}$ & $\begin{array}{l}5 \cdot 0 \\
4 \cdot 3\end{array}$ & $\begin{array}{l}18 \cdot 6 \\
20 \cdot 3\end{array}$ & $\begin{array}{l}30 \cdot 0 \\
27 \cdot 3\end{array}$ \\
\hline $\begin{array}{ll}\text { Case } 2 & \text { S.B. } \\
\text { Case } 3 & \text { H.B. } \\
\text { Case } 4 & \text { L.F. } \\
\text { Case } 5 & \text { D.F. } \\
\text { Case } 6 & \text { A.M. } \\
\text { Case } 7 & \text { L.L. }\end{array}$ & $\begin{array}{l}6 \text { yr. } 5 \text { mth. } \\
4 \text { yr. } 3 \text { mth. } \\
9 \text { yr. } \\
5 \text { yr. } \\
8 \text { yr. } 10 \mathrm{mth} . \\
2 \text { yr. } 5 \text { mth. }\end{array}$ & $\begin{array}{l}\text { R. ulnar } \\
\text { R. ulnar } \\
\text { R. ulnar } \\
\text { R. ulnar } \\
\text { R. ulnar } \\
\text { R. ulnar }\end{array}$ & $\begin{array}{l}4 \cdot 3 \\
3 \cdot 5 \\
4 \cdot 0 \\
2 \cdot 9 \\
5 \cdot 5 \\
2 \cdot 8\end{array}$ & $\begin{array}{l}5 \cdot 5 \\
6 \cdot 0 \\
4 \cdot 3 \\
2 \cdot 8 \\
2 \cdot 0 \\
4 \cdot 2\end{array}$ & $\begin{array}{l}11 \cdot 5 \\
11 \cdot 1 \\
19 \cdot 0 \\
33 \cdot 4 \\
59 \cdot 0 \\
16 \cdot 7\end{array}$ & $\begin{array}{l}15 \cdot 0 \\
12 \cdot 2 \\
18 \cdot 2 \\
34 \cdot 8 \\
63 \cdot 6 \\
29 \cdot 0\end{array}$ \\
\hline Normal values $^{2}$ & & Ulnar & $3-15$ & $0 \cdot 5-2 \cdot 0$ & 47-73 & \\
\hline
\end{tabular}

${ }^{1}$ Height of negative deflection above base line with supramaximal stimulation at elbow.

${ }^{2}$ From Thomas and Lambert (1960). 


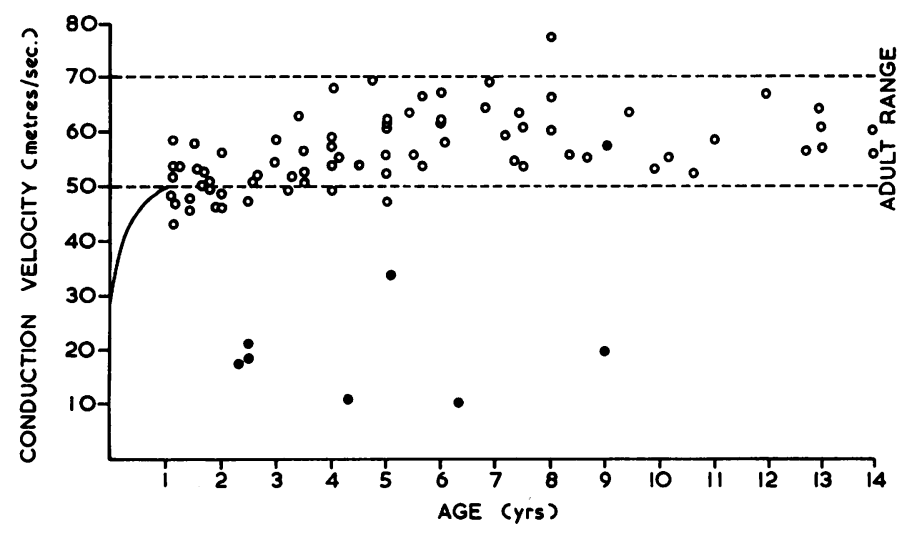

FIG. 2. Conduction velocity in motor fibres of the ulnar nerve in the forearm compared with age. Open circles are normal values of Thomas and Lambert (1960). Filled circles are from metachromatic leucodystrophy patients.

of $54.5 \mathrm{~m}$./sec. (S.D. 5.5 ) in the ulnar nerve in the forearm and $59.8 \mathrm{~m}$./sec. (S.D. 6.1) in the upper arm when recording the response through a concentric needle electrode in the abductor digiti minimi or the first dorsal interosseus muscle. From Table I it can be seen that conduction velocity was reduced in the upper arm in the six patients in whom it was reduced in the forearm.

Motor nerve conduction velocity in the median nerve in the forearm in case 1 (aged $2 \frac{1}{2}$ years) was $10.8 \mathrm{~m}$./sec. on the right and $12.7 \mathrm{~m}$. $/ \mathrm{sec}$. on the left. Gamstorp (1963) found a mean velocity of 49.5 m./sec. (S.D. 5.9) in the median nerve in the forearm in healthy children of 1 to 3 years. In case 1, therefore, there was marked slowing of conduction in both median and both ulnar nerves.

Conduction velocity in motor fibres of the lateral popliteal nerve was measured in two subjects (cases 6 and 7). In case 6 (aged 83 years) in which the findings were normal in the arm, conduction velocity was also normal in the leg. The velocity between knee and ankle was $59.5 \mathrm{~m}$./ $/ \mathrm{sec}$. The normal for the age group 3 to 8 years was found by Gamstorp (1963) to be $57.5 \mathrm{~m}$./sec. (S.D. 6.9). In case 7 (aged $2 \frac{1}{2}$ years) conduction velocity in the lateral popliteal nerve was greatly reduced, as in the arm. The velocity was $12 \cdot 1$ $\mathrm{m} . / \mathrm{sec}$; normal velocity between 1 and 3 years is 53.7 m./sec. (S.D. 8.1) (Gamstorp, 1963).

Conduction time from stimulation of the ulnar nerve at the wrist to the onset of the muscle action potential recorded from the abductor digiti minimi is shown in Table I for the seven patients. Conduction velocity cannot be calculated for this segment of nerve because delay in the fine nerve endings and at the neuromuscular junction is included in the conduction time. It can be seen that in the six patients in whom conduction velocity was reduced in the forearm and upper arm, the conduction time from the wrist was considerably greater than the highest value found by Thomas and Lambert (1960) for healthy children; this indicates that there was slowing of conduction in the distal as well as the proximal parts of the affected nerves.

In healthy subjects there is considerable individual iv variation in the strength of stimulus that must be i applied to the skin to excite all the motor fibres in a $\vec{\circ}$ nerve trunk, due to differing tissue resistances and anatomical variations in the depth of the nerve in $\frac{9}{3}$ relation to the overlying skin. However, in the patients with reduced conduction velocity, the volt $\frac{7}{0}$ age necessary for supramaximal stimulation was increased to two or three times that usually requireg in healthy children. In case 3 a rectangular pulse of $3 \mathrm{~m} . \mathrm{sec}$. duration was used (see methods) as only a few motor fibres were stimulated by the condenser discharge at the maximum available voltage (300 volts). These findings suggest that the electrical threshold of the abnormal fibres was substantially raised.

The amplitude of the muscle action potential recorded from the abductor digiti minimi when the ulnar nerve was stimulated at the elbow was measured in each case. The results are shown in Table $I$. Similar measurements were made by Thomas and Lambert (1960) in healthy children. They found that the mean amplitude gradually increased during childhood from $5.8 \mathrm{mV}$ at 3 years to $7.1 \mathrm{mV}$ at 6 years and to $10.5 \mathrm{mV}$ at 12 years, the overall range in the age group 2 to 9 years being 3 to $15 \mathrm{mV}$. Action potential

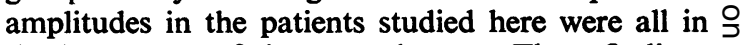
the lower part of the normal range. These findings $>$ suggest that the motor fibres were uniformly affected by the disease process; if conduction velocity in some $N$ fibres had been reduced more than in others the duration of the action potential might be expected to $N$ have increased with an associated fall in amplitude of $N$ the main deflection.

Nerve action potentials were recorded from the 0 
right ulnar nerve of case 6 , in which motor nerve conduction velocity was normal. The amplitude of the action potential recorded from the nerve at the wrist when the digital nerves of the fifth finger were stimulated through ring electrodes was $10 \mu \mathrm{V}$. and the conduction velocity of the fastest fibres was $50.0 \mathrm{~m}$. $/ \mathrm{sec}$. The amplitude of the action potential recorded from the nerve just above the elbow after stimulation at the wrist was $80 \mu \mathrm{V}$.; conduction velocity was $71.8 \mathrm{~m}$. $/ \mathrm{sec}$. in the fastest fibres. These values are all within normal limits (Gilliatt and Thomas, 1960). In this patient, therefore, no electrophysiological abnormality of the peripheral nerves has been found.

\section{DISCUSSION}

The neurological abnormalities in metachromatic leucodystrophy are mainly due to involvement of the central nervous system and it is difficult to detect minimal signs of peripheral nerve disorder. Muscle wasting does not occur and the limbs become spastic rather than flaccid as the disease progresses. Weakness of the limbs is mainly, if not entirely, due to involvement of the upper motor neurones. The tendon reflexes are, however, depressed. In the detailed clinical description of two cases by Greenfield (1933) absent tendon reflexes were noted in one child and in the second they are described as present but rather feeble. Later, Brain and Greenfield (1950) commented on the early loss of reflexes in this disease, which they say is 'not easily explained'. This finding can now be attributed to pathological changes in the peripheral nerves. Tendon reflexes were absent or depressed in all patients in the present series except in D.F. (case 5), who was at a very early stage of the disease. Detailed sensory testing was not possible in these patients. However, it is interesting that one of the children described by Greenfield (1933) complained of pins and needles in the legs and then in the arms for three months at the onset of the disease. Although this could be due to a lesion in the central nervous system, the nature and distribution of the symptoms is similar to that in many other types of peripheral neuritis.

Cutaneous nerve biopsies were carried out on five of the seven children. Typical metachromatic granules were present in all the histological sections, which also showed myelin degeneration. Webster's (1962) detailed study of the pathology of the peripheral nerves in this condition has shown that segmental demyelination occurs, similar to that seen in experimental diphtheritic neuritis (Webster et al., 1961). The myelin in the paranodal region is most severely affected but patchy disintegration of myelin in the internodes is also prominent. Long stretches of myelin in affected fibres are often normal. Recent electrophysiological studies of nerve conduction in experimental diphtheritic neuritis by McDonald (1962) and by Kaeser (1963) have shown that this type of lesion is associated with reduction of conduction velocity. Cragg and Thomas (1964) have demonstrated similar pathological changes of segmental demyelination in experimental allergic neuritis and have also shown that slowing of conduction occurs. Metachromatic leucodystrophy is a further example of a condition in which segmental demyelination is associated with reduction of nerve conduction velocity.

Metachromatic granules accumulate predominantly in the Schwann cells of the peripheral nerves. Webster (1962) found that $95 \%$ of Schwann cells were abnormal in the sections he examined. This suggests that the basic abnormality might be some defect of Schwann cell metabolism leading to disintegration of myelin, but leaving axon structure unimpaired. It seems possible that most of the abnormal nerve fibres in the patients with metachromatic leucodystrophy were still capable of conducting nerve impulses, because the amplitudes of the muscle action potential were normal or only slightly reduced despite the marked slowing of conduction. An alternative possibility, however, is that collateral sprouts from surviving nerve fibres had reinnervated muscle fibres whose nerves had degenerated.

Motor nerve conduction velocity in healthy one-month premature infants is $18-22 \mathrm{~m}$./ $/ \mathrm{sec}$. in the ulnar nerve (Thomas and Lambert, 1960). It might be postulated that the slow conduction velocity in patients with metachromatic leucodystrophy is due to failure of normal maturation of the nerve fibres. This suggestion cannot be definitely refuted at present, as serial studies on individual subjects have not been carried out. The findings in the siblings L.F. and D.F. (cases 4 and 5) are, however, of interest. The elder child was severely incapacitated and motor nerve conduction velocity was grossly reduced. Her brother was four years younger and had only a short history and slight clinical involvement. Conduction in the latter patient, although abnormal, was faster than in his sister. This observation would be more in keeping with the suggestion that conduction slows as the disease progresses. The pathological findings are also more consistent with this view.

There is no obvious explanation for the normal findings in one child (case 6) in contrast to the marked abnormalities in the other six. Although in this patient the disease ran an atypical clinical course, starting at an older age than usual with a progressive dementia, the sections obtained by cerebral and rectal biopsy showed characteristic metachromatic 
material. Peripheral nerve biopsy has not been carried out. The other cases are all classical examples of the late infantile variety of Greenfield.

The value of peripheral nerve and rectal biopsy in the diagnosis of metachromatic leucodystrophy has already been established. The present study has shown that the simple technique of measuring motor nerve conduction velocity can be applied as a screening test for selecting cases in which peripheral nerve biopsy is likely to lead to a correct diagnosis.

\section{SUMMARY}

Peripheral nerve conduction has been studied in seven children suffering from metachromatic leucodystrophy. In six there was a marked reduction of motor nerve conduction velocity. The amplitudes of the muscle action potentials were at the lower limit of the normal range. In the seventh patient no electrophysiological abnormality was found.

\section{CASE REPORTS}

CASE 1 E.D., a girl, was born on 20 March 1960 (G.O.S. 340310).

Her early milestones were normal but from 16 months she made no progress in walking and fell frequently. At 2 years she developed a tremor of her limbs and marked unsteadiness of her arms and legs. These symptoms gradually became more marked until she was completely helpless.

On examination when aged 2 years 7 months she was mute, with marked nystagmus in all directions of gaze, and had incoordinate eye movements. There was severe rigidity of all limbs with only a little spontaneous movement of the arms and none of the legs. All tendon reflexes were absent and both plantar responses were extensor.

Biopsy of the rectum and skin showed accumulation of metachromatic granules around nerve fibres. Urinary deposit showed similar metachromatic material in epithelial cells.

CASE 2 S.B., a boy, was born on 25 June 1956 (G.O.S. 311582).

This child's milestones were slightly retarded and he never learnt to walk unaided. Definite deterioration of motor performance was noticed from 16 months and has been progressive. Since the age of 3 he has been confined to bed and unable to speak. He developed jerky movements of the eyes and began to have difficulty in swallowing.

On examination at 6 years 5 months he had nystagmus in all directions of gaze. His limbs were rigid with practically no voluntary movement. All tendon reflexes were absent and both plantar responses were extensor.

Cerebral biopsy, when aged $4 \frac{1}{2}$ years, established the diagnosis of metachromatic leucodystrophy. Biopsy of the lateral cutaneous nerve of the thigh, when aged $6 \frac{1}{2}$ years, showed metachromatic material in the nerve trunk. A portion of the nerve treated with osmic acid showed myelin degeneration of a few fibres, but most were devoid $\mathbb{D}$ of myelin. Metachromatic granules were also present around nerves in the rectum and in epithelial cells in the urine.

CASE 3 H.B., a girl, was born on 5 August 1958 (G.O.S 342723).

This child was a younger sister of S.B. She developed normally for one year, when she was noticed to have wobbly eyes. At 14 months her gait became clumsy and her speech slurred. She gradually deteriorated and by $3 \stackrel{\vec{\rho}}{\vec{S}}$ years could not speak and had difficulty in swallowing $\overline{0}$ Her limbs became increasingly stiff.

On examination when aged 4 years 3 months she had $\frac{\bar{c}}{\bar{n}}$ bilateral primary optic atrophy with impaired conjugate $\overrightarrow{\widetilde{\sigma}}$ eye movements. Her limbs were spastic with no voluntary $\varrho$ movement, all tendon reflexes were absent and both plan-» tar responses extensor.

Sections obtained by biopsy of the lateral cutaneous. nerve of the thigh were very similar to those of her brother $\vec{A}$ S.B.; metachromatic granules were present and most of ${ }^{\omega}$ the fibres had no myelin. Metachromatic granules were $\bar{z}$ also seen around nerves in the rectum and in urinary epithelial cells.

She died in May 1963 aged 4 years 9 months.

CASE 4 L.F., a girl, was born on 17 May 1954 (G.O.S. $\vec{\circ}$ 247908).

This child developed normally until the age of 4 years $\bigcirc$ when she became slightly unsteady. From $5 \frac{1}{2}$ years deteriorated more rapidly with slurring of speech, in $\frac{7}{0}$ creasing unsteadiness, and mental deterioration. Ato 7 . years she had a left focal epileptic attack. By 9 years $\overrightarrow{s e} \cdot \overrightarrow{0}$ was completely helpless, had lost her speech, and doubly incontinent. She had several grand mal seizures. during one day.

When first examined aged $5 \frac{1}{2}$ years she had an ataxic gait and bilateral extensor plantar responses. There were no other neurological abnormalities and, in particular, tendon reflexes were normal. Over the next 18 months herס speech became slurred and she developed tremor of the limbs. At the last examination, aged 9, she had bilateralö optic atrophy and gross spasticity of the limbs with 3 minimal movement of the arms and none of the legs. Tendon reflexes were still present in the arms but knee and ankle jerks were absent. Plantar responses were extensor:

Biopsies of cerebral cortex, sural nerve, rectum, and skin all showed metachromatic granules around the nerve fibres. Osmic-acid-treated sections of sural nerve showed 3 that most fibres were devoid of myelin. There was abund-ant metachromatic material in epithelial cells in the urine.

CASE 5 D.F., a boy, was born on 20 May 1958 (G.O.S.윽 340194).

This patient was the younger brother of L.F. Between $1 \frac{1}{2}$ and 4 years he had three grand mal epileptic attacks in association with infective illnesses (rubella, tonsillitis, and $\sigma$ pyrexia of unknown cause). Otherwise he developedn normally until 4 years 10 months when he developed slurring of speech and a clumsy gait, becoming more un- $\bar{\sigma}$
steady during the next two months.

On examination when aged 5, apart from dysarthria,, 
there were no abnormalities in the cranial nerves. Tone in the legs was slightly increased, there was no weakness but incoordination was present, particularly on walking. Tendon reflexes were normal in the arms and increased in the legs; the plantar responses were extensor. There was no abnormality of sensation.

Biopsies of sural nerve, rectum, and skin showed degeneration of nerve fibres with metachromatic granules around the nerve fibres.

CASE 6 A.M., a boy, was born on 13 December 1953 (G.O.S. 335804).

This boy was normal until 6 years 3 months when he developed an acute illness with jaundice. He recovered after a month but from this time his school reports deteriorated. He had a further episode of jaundice a year later, which was followed by rapid mental deterioration. At his first hospital admission nine months later, aged 8 years, he was severely demented and doubly incontinent, but no abnormal focal neurological signs were present. Over the next few months he became unsteady on his feet, developed progressive limb weakness and lost his speech.

On examination when aged 8 years 10 months the cranial nerves were normal. He had marked rigidity with fixed flexion of all his limbs. A little voluntary movement was present in the hands and feet only. Tendon reflexes were absent in the arms. Knee and ankle jerks were present and both plantar responses were extensor.

Cerebral biopsy showed typical changes of metachromatic leucodystrophy. Biopsy of rectum and skin showed metachromatic material in association with some nerve fibres. Peripheral nerve biopsy was not performed. Urine deposit contained metachromatic granules.

CASE 7 L.L., a girl, was born on 3 January 1961 (G.O.S. 353364).

This child developed normally until the age of 19 months when she began to fall backwards. Four months later weakness of the left leg was noticed. A month later she had an acute illness with vomiting, diarrhoea, and high fever for a week, following which her neurological state deteriorated more rapidly. She developed stiffness of the legs and increasing difficulty in walking, and a few months later her speech and mental state gradually deteriorated.
On examination when aged 2 years 6 months she had little spontaneous speech. Cranial nerves were normal. Power in the arms was normal, but movements were incoordinate, with intention tremor. Her legs were spastic, with marked weakness and incoordination, and she had severe trunk ataxia. Tendon reflexes were absent in the arms and brisk in the legs; plantar responses were flexor. Biopsy of rectum, skin, and sural nerve showed abundant metachromatic material in association with nerve fibres and there was fragmentation of myelin sheaths. Metachromatic granules were also present in the urine.

I would like to thank Dr. Raymond Adams and Dr. R. W. Gilliatt for drawing my attention to the peripheral nerve changes in metachromatic leucodystrophy. I would also like to thank Dr. P. Sandifer for allowing me to investigate the patients, all of whom were under his care at the Hospital for Sick Children, Great Ormond St., London, and for his interest; Dr. H. Metz for his help in arranging for the patients to be available; Professor W. Blackwood, Dr. W. G. P. Mair, and the late Dr. M. Bodian for the pathological reports, and the editors of the Journal of Applied Physiology for permission to reproduce Figure 2.

\section{REFERENCES}

Bertrand, I., Thieffry, S., and Bargeton, E. (1954). Rev. neurol., 91, 161.

Bodian, M., and Lake, B. D. (1963). Brit. J. Surg., 50, 702.

Brain, W. R., and Greenfield, J. G. (1950). Brain, 73, 291.

Cragg, B. G., and Thomas, P. K. (1964). J. Neurol. Neurosurg. Psychiat., 27, 106.

Dawson, G. D. (1956). J. Physiol. (Lond.), 131, 436.

Fullerton, P. M. (1963). Electroenceph. clin. Neurophysiol., 15, 913.

Gamstorp, I. (1963). Acta paediat. (Uppsala), suppl. 146, p. 68.

Gilliatt, R. W., and Thomas, P. K. (1960). J. Neurol. Neurosurg. Psychiat., 23, 312

Greenfield, J. G. (1933). J. Neurol. Psychopath., 13, 289.

Hagberg, B., Sourander, P., and Thorén, L. (1962). Acta paediat., suppl. 135, p. 63

Jacobi, M. (1947). Virchows Arch. path. Anat., 314, 460.

Kaeser, H. E. (1963). Bibl. psychiat. neurol. (Basel), Bibl. Fasc. 120.

McDonald, W. I. (1962). Acta neuropath. (Berl.), 1, 425.

Norman, R. M., Urich, H., and Tingey, A. H. (1960). Brain, 83, 369.

Thieffry, S., and Lyon, G. (1959). Rev. neurol., 100, 452.

Thomas, J. E., and Lambert, E. H. (1960). J. appl. Physiol., 15, 1.

Thomas, P. K., and Morton, H. B. (1963). Electroenceph. clin. Neurophysiol., 15, 691.

Webster, H. deF. (1962). J. Neuropath. exp. Neurol., $21,534$.

$\longrightarrow$, Spiro, D., Waksman, B., and Adams, R. D. (1961). Ibid., 20, 5. 